Provided for non-commercial research and education use. Not for reproduction, distribution or commercial use.

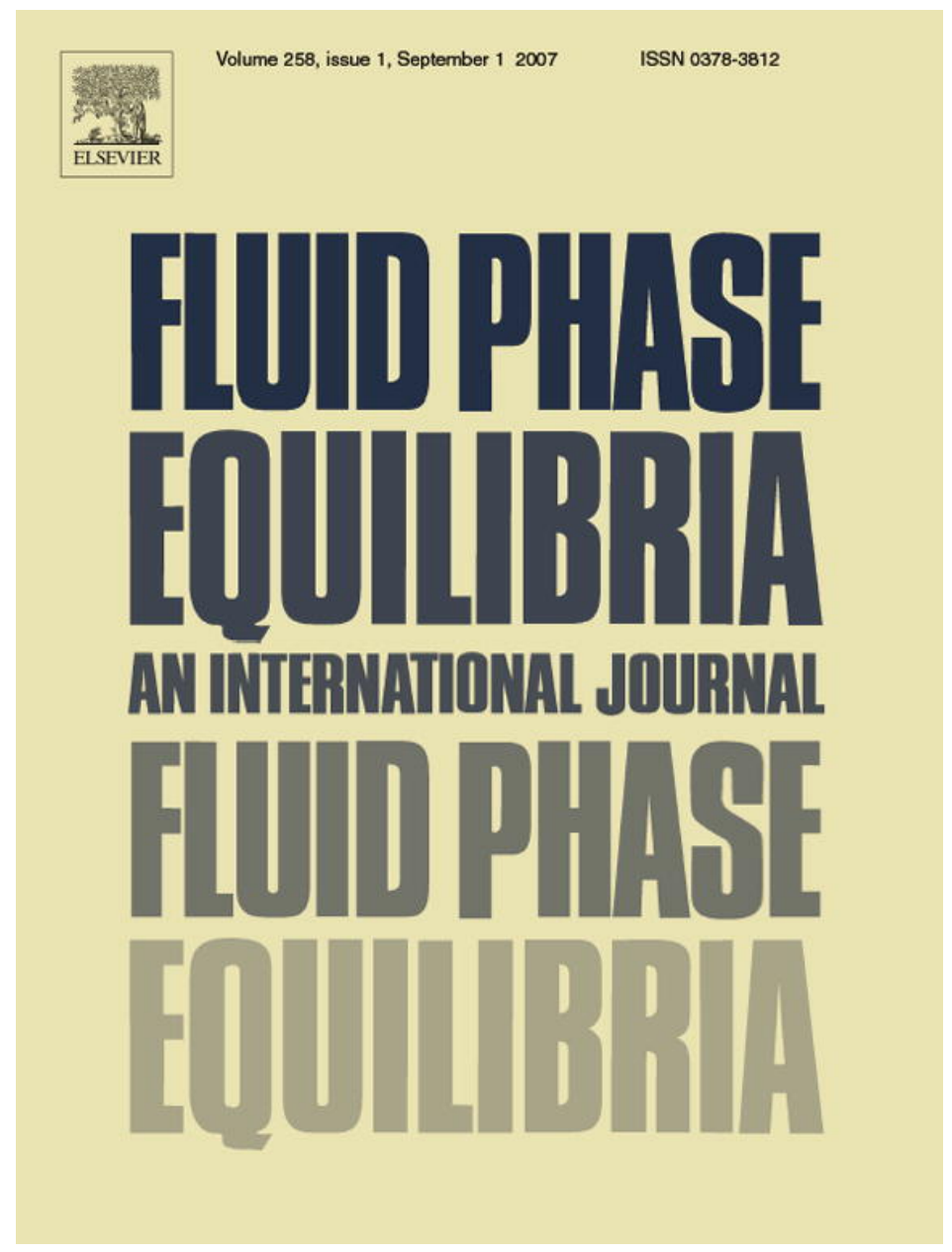

This article was published in an Elsevier journal. The attached copy

is furnished to the author for non-commercial research and education use, including for instruction at the author's institution, sharing with colleagues and providing to institution administration.

Other uses, including reproduction and distribution, or selling or licensing copies, or posting to personal, institutional or third party websites are prohibited.

In most cases authors are permitted to post their version of the article (e.g. in Word or Tex form) to their personal website or institutional repository. Authors requiring further information regarding Elsevier's archiving and manuscript policies are encouraged to visit:

http://www.elsevier.com/copyright 


\title{
Mutual solubilities of hydrocarbons and water with the CPA EoS
}

\author{
M.B. Oliveira ${ }^{\text {a }}$, J.A.P. Coutinho ${ }^{\text {a }}$, A.J. Queimada ${ }^{b}, *$ \\ ${ }^{a}$ CICECO, Chemistry Department, University of Aveiro, 3810-193 Aveiro, Portugal \\ ${ }^{\mathrm{b}}$ Laboratory of Separation and Reaction Engineering (LSRE), Faculdade de Engenharia, \\ Universidade do Porto, Rua do Dr. Roberto Frias, 4200-465 Porto, Portugal
}

Received 8 March 2007; received in revised form 16 May 2007; accepted 22 May 2007

Available online 29 May 2007

\begin{abstract}
The knowledge of hydrocarbon/water phase equilibria is important in the design and operation of equipment for petroleum transport and refining and petrochemical plants. The presence of water in a hydrocarbon mixture can affect the product quality and damage the operation equipment due to corrosion and formation of gas hydrates. Tracing the concentration of hydrocarbons in aqueous media is also important for technical purposes like preventing oil spills and for ecological concerns such as predicting the fate of these organic pollutants in the environment.

In spite of its huge interest there was no model able for a qualitative description of the mutual solubility of water and hydrocarbons for a broad range of systems in a wide range of thermodynamic conditions.

In this work it is shown that an equation of state incorporating association known as the CPA EoS is able to produce an excellent description of the mutual solubilities of water and several aliphatic and aromatic hydrocarbons in a broad range of pressures and temperatures.
\end{abstract}

(C) 2007 Elsevier B.V. All rights reserved.

Keywords: CPA; Phase equilibria; Water; Hydrocarbons; High pressure

\section{Introduction}

Describing the mutual solubilities of hydrocarbons and water is very important in the energy industry. Natural gas is generally saturated with water and during production, transportation, and processing, some of the dissolved water in the vapor phase may condense. Predicting the water solubility in a hydrocarbon mixture to prevent the formation of this aqueous phase is necessary to conform to product specifications and to protect the operation equipment from corrosion, the most common adverse effect. Imposing a maximum value for the water solubility is also necessary even when a water rich phase is deliberately created for the transport of heavy oils or to remove salts that deposit on the pipelines [1].

Abbreviations: AAD, average absolute deviation; APACT, associated perturbed anisotropic chain theory; CPA, cubic plus association; EoS, equation of state; LLE, liquid-liquid equilibria; MHV2, second-order modified Huron-Vidal mixing rules; NP, number of data points; SAFT, statistical associating fluid theory; SRK, Soave-Redlich-Kwong; UNIFAC, universal functional activity coefficient model

* Corresponding author. Tel.: +351 22508 1686; fax: +351 225081674 .

E-mail address: ajq@fe.up.pt (A.J. Queimada).
Beside corrosion, the presence of water in hydrocarbon mixtures, can also lead to the formation of gas hydrates which can cause problems in the petroleum industry, since they can form in pipelines and block the flow during transportation, drilling and production of oil or natural gas. They can also cause the hampering of the operation of heat exchangers and expanders. Thus, modeling the water content is required to determine the extent of drying or the amount of gas hydrate inhibitor necessary to avoid gas hydrate formation [2,3]. On the other hand gas hydrates can be used as an unconventional natural gas energy storage since the gas hydrates can contain more than 150 times as much natural gas than gaseous natural gas at standard temperature and pressure. Most light hydrocarbons are known to form stable gas hydrates only under high pressure and low temperature conditions [4].

Being able to model the water solubility in hydrocarbon fluids is also useful in predicting the water content of fuels.

The knowledge of the phase equilibria of aqueous mixtures with hydrocarbons is important for environmental purposes since hydrocarbons, like other pollutants, must be removed from refinery and petrochemical plant wastewater streams and from sea or fresh waters when oil spills occur. For this purpose, knowing the solubility and volatility of hydrocarbons is required 
to describe their phase distribution through the removal process and also to assist in the design of separation equipment [1].

Despite the importance of these systems it is quite difficult to describe their phase equilibria since aqueous solutions of hydrocarbons have an extreme nonideal behavior resulting in a very limited miscibility over a broad temperature range. Moreover the solubility of a hydrocarbon in water is several orders of magnitude lower than the counterpart solubility of water in the hydrocarbon. In addition, the solubility of hydrocarbons in water has a minimum value at lower temperatures (where the enthalpy of solution is zero), while the water solubility in hydrocarbons is a monotonic function of temperature [5].

Over the last three decades a number of approaches to the description of the mutual solubilities of hydrocarbons and water have been attempted. Several quantitative structure-property relationships (QSPR) have been used to estimate the solubility of organic compounds in water. The hydrocarbon content can be correlated with the molecular surface area [6], the different group contributions or fragment structure information [7]. These QSPRs can also involve self-organizing maps (SOMs) and fuzzy ARTMAP neural systems, as in the work of Giralt et al., developed to estimate infinite dilution activity coefficients of organics compounds in water [8].

Also, different thermodynamic models have been evaluated for hydrocarbon/water mutual solubilities. The property of practical interest for the description of low pressure mutual solubilities is the Henry's law constant which is a direct measure of the partition of a given solute between two phases. This property expressed as a function of temperature and pressure is useful for correlating or predicting hydrocarbon solubility in water, provided that the fugacity of the coexisting organic phase can be calculated. A group contribution scheme based on a hydration model was already used to predict the Henry's law constant of aqueous systems of alkanes, alkenes, alkylcycloalkanes, and alkylbenzenes [9].

However, until recently the state of art model for water solubility modeling was the UNIFAC model, in spite of its poor accuracy for the systems under study. In fact, the existing UNIFAC-type models perform poorly when applied to the prediction of infinite-dilution activity coefficients in polar mixtures, especially in aqueous mixtures [10]. Even the model of Hooper et al. [11] which was developed only to correlate liquid-liquid equilibria for water/hydrocarbon mixtures, degrades its performance as the carbon number in the $n$-alkane increases. Empirical approaches are possible to overcome these limitations but involve reducing the general predictive character of the group contribution [12]. Moreover this model is limited to low pressure applications. There are better alternative approaches for UNIFAC that are specifically designed for aqueous solutions such as the linear solvation energy relationship (LSER) but work is still in progress to increase its range of applicability [13]. Other activity coefficient models, such as the non-random two liquid model (NRTL), was also used in combination with the Debye-Hückel theory to calculate the solubility of a number of molecular solutes in water in the presence of a hydrotope [14].
The extension to high pressures was first achieved through excess Gibbs energy models in cubic equation of state mixing rules $\left(\right.$ EoS- $\left.G^{E}\right)$ such as the modified Huron-Vidal, mixing rules (MHV2), but still with limited success towards the mutual solubilities of water and hydrocarbons [15].

A novel, a priori prediction method for thermodynamic equilibria of fluids is COSMO-RS. This method was used to predict the mutual solubilities of hydrocarbons and water with a good qualitative and an even satisfactory quantitative agreement with the experimental data. Further improvements of the hydrogen bond temperature dependence in COSMO-RS parameterizations or the inclusion of the shape effects existing in pure chain liquids, for instance, are still necessary to improve the description of mutual solubilities of hydrocarbons and water [16].

Recently, Bidart et al. employed the Carnahan Starling van der Waals equation of state with quadratic mixing rules for obtaining the global phase diagrams of water $+n$-alkane mixtures $[n=1-36]$ with qualitative agreement with experimental results [17].

The breakthrough in the modeling of aqueous systems came with the development of association models such as the statistical associating fluid theory (SAFT) [18], the associatedperturbed-anisotopic-chain-theory (APACT) [5] and the cubic plus association (CPA) EoS [18-20]. All these models have previously been applied to the description of the hydrocarbon/water mutual solubilities and the SAFT EoS was already applied for the prediction of the thermodynamic inhibiting effect of methanol on gas hydrate formation [21]. However, the original SAFT approach has problems in describing aqueous solutions of hydrocarbons. As shown by Economou and co-workers [5,22], increasing the complexity of SAFT and explicitly accounting for hydrogen bonding, by several mixing rules and association schemes for water, does not improve the fitting of the water solubility neither provide a quantitative description of the hydrocarbon solubility. Possible explanations for the SAFT limitations in these systems are its inadequacy to account for the high polarity of the water molecule, or the use of inappropriate water parameters. The same study showed that the APACT model when applied for aqueous hexane and decane systems provided hydrocarbon solubilities too low by one to four orders of magnitude, and that the 3-site model predicts a minimum in the aromatic hydrocarbon solubility but at much higher temperatures and solubilities than the experimental values.

After the original development of the SAFT model several new versions were proposed for modeling hydrocarbon/water binary systems. The Lennard-Jones SAFT (LJ-SAFT), exhibited better agreement with experimental data than the original version, however it can only be applied to a limited range of density [23]. Grenner et al., employed the simplified perturbed chain SAFT model (PC-SAFT) using a different set of water pure component parameters based on some physically justified arguments to predict very satisfactorily the solubilities in the hydrocarbon rich phase but the obtained solubility of the hydrocarbon in water was higher than the experimental values [24]. Improved results were also recently obtained by Karakatsani et al. using a polar term in PC-SAFT (tPC-SAFT). With a polar contribution, mutual solubilities of water $+n$-hexane and 
water + cyclohexane were better described, when compared with PC-SAFT without the polar contribution [25]. Other version of SAFT, Soft-SAFT has also shown to be able to model mutual solubilities of water $+n$-alkanes and water + benzene systems, including the description of the minima on the hydrocarbon solubility in water [26], but unfortunately, these results were not yet further investigated in the open literature.

Other association equations of state like the Elliot-SureshDonohue EoS [27] and the Wu-Prausnitz EoS [28] (that is basically CPA but with the Peng-Robinson cubic term instead of the most commonly used Soave-Redlich-Kwong term) have also shown to provide satisfactory results for water-alkane systems. Nevertheless the results obtained until present seem to indicate that within the association equations of state the CPA EoS is the most successful association model for the description of water containing systems, with alkanes, alkenes, cycloalkanes [29], aromatics [30], alcohols [31] glycols [32] and perfluorocarbons [33].

In this work, the ability of the CPA EoS to model the liquid-liquid equilibria of hydrocarbons + water systems in wide ranges of pressure and temperature is here demonstrated. This equation of state combines the Soave-Redlich-Kwong (SRK) cubic equation of state for describing the physical interactions with the association contribution proposed by Wertheim [34]. It will be shown that CPA can provide an accurate description of the liquid-liquid equilibria of aqueous mixtures with hydrocarbons, being a single temperature independent binary interaction parameter, $k_{i j}$, the only required parameter for modeling the aqueous solubility of aliphatic compounds. For aromatic hydrocarbons, an additional solvation parameter that takes into account the cross-association phenomena between water and aromatic hydrocarbons is required. In both cases, the values of these binary parameters are very small, thus indicating the adequacy of the CPA EoS for these phase equilibria calculations. A correlation for the $k_{i j}$ parameter will be also proposed making this approach predictive for alkanes.

\section{Model}

The CPA equation of state, in terms of the compressibility factor, can be expressed as the sum of two contributions: one accounting for physical interactions, that in the current work is taken as the SRK EoS, and another accounting for association, the Wertheim association term [22,28,34]:

$$
\begin{aligned}
Z= & Z^{\text {phys. }}+Z^{\text {assoc. }} \\
= & \frac{1}{1-b \rho}-\frac{a \rho}{R T(1+b \rho)}-\frac{1}{2}\left(1+\rho \frac{\partial \ln g}{\partial \rho}\right) \\
& \sum_{i} x_{i} \sum_{\mathrm{A}_{i}}\left(1-X_{\mathrm{A}_{i}}\right)
\end{aligned}
$$

where $a$ is the energy parameter, $b$ the co-volume parameter, $\rho$ the density, $g$ the simplified radial distribution function [35], $X_{\mathrm{A}_{i}}$ the mole fraction of pure component $i$ not bonded at site $\mathrm{A}$ and $x_{i}$ is the mole fraction of component $i$.
The pure component energy parameter of CPA has a Soavetype temperature dependency:

$a(T)=a_{0}\left[1+c_{1}\left(1-\sqrt{T_{\mathrm{r}}}\right)\right]^{2}$

where $a_{0}$ and $c_{1}$ are regressed (simultaneously with $b$ ) from pure component vapor pressure and liquid density data. When CPA is extended to mixtures, the energy and co-volume parameters of the physical term are calculated employing the conventional van der Waals one-fluid mixing rules:

$a=\sum_{i} \sum_{j} x_{i} x_{j} a_{i j}, \quad a_{i j}=\sqrt{a_{i} a_{j}}\left(1-k_{i j}\right)$

and

$b=\sum_{i} x_{i} b_{i}$

$X_{\mathrm{A}_{i}}$ is related to the association strength $\Delta^{\mathrm{A}_{i} \mathrm{~B}_{j}}$ between two sites belonging to two different molecules and is calculated by solving the following set of equations:

$X_{\mathrm{A}_{i}}=\frac{1}{1+\rho \sum_{j} x_{j} \sum_{\mathrm{B}_{j}} X_{\mathrm{B}_{j}} \Delta^{\mathrm{A}_{i} \mathrm{~B}_{j}}}$

where

$\Delta^{\mathrm{A}_{i} \mathrm{~B}_{j}}=g(\rho)\left[\exp \left(\frac{\varepsilon^{\mathrm{A}_{i} \mathrm{~B}_{j}}}{R T}\right)-1\right] b_{i j} \beta^{\mathrm{A}_{i} \mathrm{~B}_{j}}$

where $\varepsilon^{\mathrm{A}_{i} \mathrm{~B}_{j}}$ and $\beta^{\mathrm{A}_{i} \mathrm{~B}_{j}}$ are the association energy and the association volume, respectively.

The simplified radial distribution function, $g(\rho)$ is given by [35]

$g(\rho)=\frac{1}{1-1.9 \eta} \quad$ where $\quad \eta=\frac{1}{4} b \rho$

For non-associating components CPA has three pure component parameters $\left(a_{0}, c_{1}\right.$ and $\left.b\right)$ while for associating components it has five $\left(a_{0}, c_{1}, b, \varepsilon, \beta\right)$. In both cases, parameters are regressed simultaneously from vapor pressure and liquid density data. The objective function used is

$\mathrm{OF}=\sum_{i}^{N P}\left(\frac{P_{i}^{\text {exp }}-P_{i}^{\text {calc. }}}{P_{i}^{\text {exp } .}}\right)^{2}+\sum_{i}^{N P}\left(\frac{\rho_{i}^{\text {exp } .}-\rho_{i}^{\text {calc. }}}{\rho_{i}^{\text {exp }}}\right)^{2}$

For a binary mixture composed by a self-associating and a non-associating compound, as for example the water $+n$ alkanes systems, the binary interaction parameter $k_{i j}$ is the only adjustable parameter and thus no combining rules are required for the association energy and volume.

When CPA is employed to mixtures containing crossassociating molecules, which is the case of the systems with aromatic hydrocarbons and $\mathrm{H}_{2} \mathrm{O}$ studied in this work, combining rules for the association energy and volume parameters are required [30,36]. For these systems the approach suggested by Folas et al. [30] was adopted. The cross-association energy between aromatic hydrocarbons and water is taken as half the water association energy and the cross association volume 
$\left(\beta^{\mathrm{A}_{i} \mathrm{~B}_{j}}\right)$ is used as an adjustable parameter fitted to equilibrium data:

$\varepsilon^{\mathrm{A}_{\text {aromatic }} \mathrm{B}_{\mathrm{H}_{2} \mathrm{O}}}=\frac{\varepsilon^{\mathrm{A}_{\mathrm{H}_{2} \mathrm{O} \mathrm{B}_{\mathrm{H}_{2} \mathrm{O}}}}}{2}$

For estimating the $k_{i j}$ and $\beta^{\mathrm{A}_{i} \mathrm{~B}_{j}}$ parameters the following objective function was employed:

$\mathrm{OF}=\sum_{i}^{N P}\left(\frac{x_{i}^{\text {calc. }}-x_{i}^{\text {exp } .}}{x_{i}^{\exp } \cdot}\right)^{2}$

where single phase or all phase data can be selected during the parameter optimization.

Eq. (5) shows that the association term depends on the number and type of association sites for the associating compound. For water a four-site (4C) association scheme was adopted since it is considered that hydrogen bonding occurs between the two hydrogen atoms and the two lone pairs of electrons in the oxygen of the water molecules.

For the aromatics compounds a single association site is considered, cross associating with water, as suggested by some theoretical and experimental evidence $[37,38]$.

\section{Results and discussion}

The hydrocarbons studied in this work are all non self associating. The CPA parameters for these pure compounds are thus only the three parameters required for the physical part. These parameters have been estimated by a simultaneous regression of selected vapor pressure and saturated liquid density data, col- lected from the DIPPR database [39], covering the range of reduced temperatures from 0.45 to 0.85 . The pure compound parameters for the studied aliphatic and aromatic hydrocarbons and for water are reported in Table 1. An excellent description of the experimental vapor pressure and liquid densities is achieved with CPA, with a global average deviation of $0.8 \%$ for both properties. For methane, a very good description of vapour pressures and densities was achieved using the critical properties and the conventional definition of the $a$ and $b$ parameters. For this reason, it was decided not to re-estimate the methane pure compound parameters. The values reported in Table 1 are the values obtained using the critical properties, considering the similarity of Eq. (2) with the traditional Soave expression.

In a previous work we demonstrated that the pure compound parameters of the physical part of CPA for the $n$-alkanes seem to follow a trend within the homologous series, what allows the CPA EoS to be used as a predictive tool for this family of compounds. Quadratic and linear correlations for the variation of these parameters with the van der Waals volume were proposed in that study [40].

Having estimated the pure compound parameters it is now possible to describe binary mixtures. For light $n$-alkanes, from methane to butane, an extensive experimental database for the mutual solubilities of these systems is available in a large range of temperature (298.15-573.15 K) and pressure (0.1-200 MPa) [41-54]. To provide a good description of these experimental data, for each system a single, temperature independent, binary interaction parameter was required. For these lighter $n$ alkanes + water, as the evaluating database contained both LLE and VLE data, the fit of the $k_{i j}$ parameter was performed against

Table 1

Pure component CPA parameters and deviations on the description of saturation pressures and densities

\begin{tabular}{|c|c|c|c|c|c|c|c|}
\hline \multirow[t]{2}{*}{ Compound } & \multirow[t]{2}{*}{$a_{0}\left(\mathrm{~Pa} \mathrm{~m}^{6} \mathrm{~mol}^{-2}\right)$} & \multirow[t]{2}{*}{$c_{1}$} & \multirow[t]{2}{*}{$b\left(\times 10^{5} \mathrm{~m}^{3} \mathrm{~mol}^{-1}\right)$} & \multirow[t]{2}{*}{$\varepsilon\left(\mathrm{J} \mathrm{mol}^{-1}\right)$} & \multirow[t]{2}{*}{$\beta$} & \multicolumn{2}{|c|}{$\% \mathrm{AAD}$} \\
\hline & & & & & & $P^{\sigma}$ & $\rho_{\text {liq. }}$ \\
\hline Methane & 0.23 & 0.46 & 2.95 & & & 0.45 & 1.71 \\
\hline Ethane & 0.55 & 0.59 & 4.30 & & & 0.09 & 1.10 \\
\hline Propane & 0.92 & 0.67 & 5.89 & & & 0.29 & 0.81 \\
\hline Butane & 1.35 & 0.73 & 7.48 & & & 0.25 & 0.68 \\
\hline Pentane & 1.82 & 0.80 & 9.13 & & & 0.45 & 0.60 \\
\hline Hexane & 2.34 & 0.87 & 10.80 & & & 0.54 & 0.63 \\
\hline Heptane & 2.89 & 0.93 & 12.50 & & & 1.17 & 0.57 \\
\hline Octane & 3.47 & 1.00 & 14.22 & & & 1.02 & 0.67 \\
\hline Decane & 4.74 & 1.11 & 17.65 & & & 1.24 & 1.45 \\
\hline Benzene & 1.79 & 0.77 & 7.54 & & & 0.83 & 0.50 \\
\hline Toluene & 2.32 & 0.83 & 9.21 & & & 0.24 & 0.47 \\
\hline$o$-Xylene & 2.92 & 0.88 & 10.86 & & & 0.59 & 1.08 \\
\hline$m$-Xylene & 2.91 & 0.88 & 10.91 & & & 0.45 & 0.55 \\
\hline$p$-Xylene & 2.83 & 0.75 & 11.10 & & & 1.86 & 1.87 \\
\hline 1,3,5-Trimethylbenzene & 3.48 & 0.94 & 12.50 & & & 0.79 & 0.21 \\
\hline Ethylbenzene & 2.87 & 0.87 & 10.85 & & & 0.85 & 0.56 \\
\hline Propylbenzene & 3.36 & 0.90 & 12.14 & & & 0.67 & 0.63 \\
\hline Butylbenzene & 4.05 & 0.97 & 14.17 & & & 0.77 & 0.94 \\
\hline Pentylbenzene & 4.76 & 1.02 & 16.07 & & & 1.89 & 0.73 \\
\hline Isopropilbenzene & 3.38 & 0.97 & 12.84 & & & 0.86 & 0.41 \\
\hline Styrene & 2.66 & 0.82 & 9.48 & & & 1.45 & 1.02 \\
\hline Water & 0.12 & 0.67 & 1.45 & 16.655 & 0.069 & 0.73 & 0.82 \\
\hline Average deviation & & & & & & 0.79 & 0.82 \\
\hline
\end{tabular}


Table 2

Deviations in the water $+n$-alkane mutual solubilities expressed in mol fractions obtained from CPA and respective binary interaction parameter values

\begin{tabular}{llll}
\hline Compound & $k_{i j}$ & AAD \% & \\
\cline { 3 - 4 } & & $\begin{array}{l}x \text { water in hydrocarbon- } \\
\text { rich phase }\end{array}$ & $\begin{array}{l}x \text { hydrocarbon in } \\
\text { water-rich phase }\end{array}$ \\
\hline Methane & 0.165 & 12.8 & 29 \\
Ethane & 0.141 & 12.2 & 21.7 \\
Propane & 0.117 & 38.8 & 22.5 \\
Butane & 0.092 & 51.9 & 35.1 \\
Pentane & 0.068 & 26.3 & 20.4 \\
Hexane & 0.044 & 19.3 & 22.7 \\
Heptane & 0.019 & 23.7 & 41.9 \\
Octane & -0.005 & 17.9 & 34.8 \\
Decane & -0.054 & 29.2 & 41.2 \\
Average deviation & 25.8 & 30.0 \\
\hline
\end{tabular}

all the available phase data. This allows to obtain a single $k_{i j}$ able to describe all the fluid phase equilibria in these systems. For the remaining of the systems in this work, which only involve LLE, the kij was fitted to the aqueous phase and used to predict the behavior of the hydrocarbon-rich phase. Therefore with this single value of $k_{i j}$ it was possible to describe the mutual solubilities with a global average deviation of 30 and $26 \%$ for the hydrocarbon solubility in the water-rich phase and for the water solubility in the hydrocarbon-rich phase, respectively, as reported in Table 2 and as can be seen in Figs. 1 and 2. The CPA EoS was successfully applied to extreme conditions of temperature and pressure, lower deviations would be expected if the CPA EoS was used to model narrow ranges of temperature and pressure.

For higher $n$-alkanes from pentane to decane mutual solubilities were available at the three-phase equilibrium pressure [1,55-58]. As before a single, temperature independent, binary interaction parameter was enough to adequately describe the phase equilibria. Values for the binary interaction parameters and for the average deviations in the mutual solubilities are presented in Table 2.

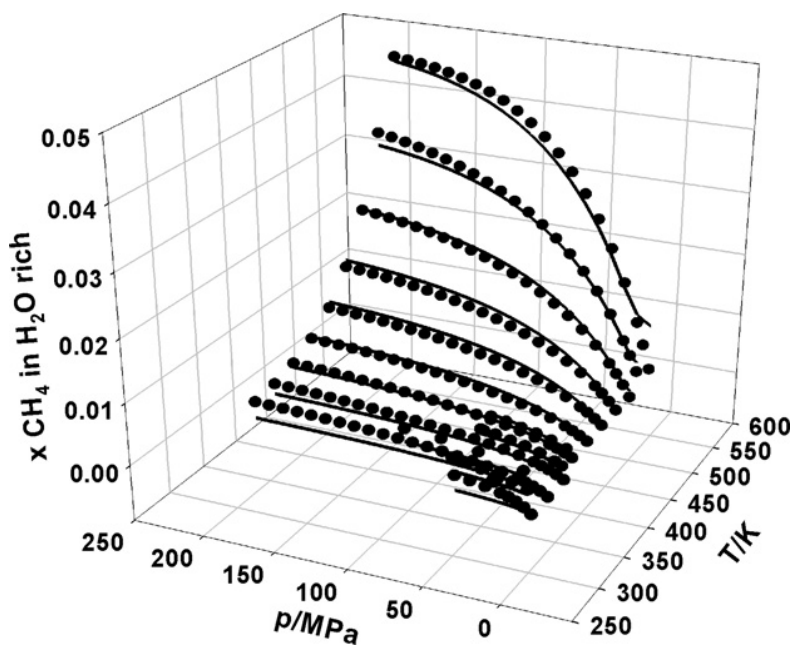

Fig. 1. Methane solubility in the aqueous-rich phase (experimental $(\bullet)$ and CPA results using $\left.k_{i j}=0.165(-)\right)$.

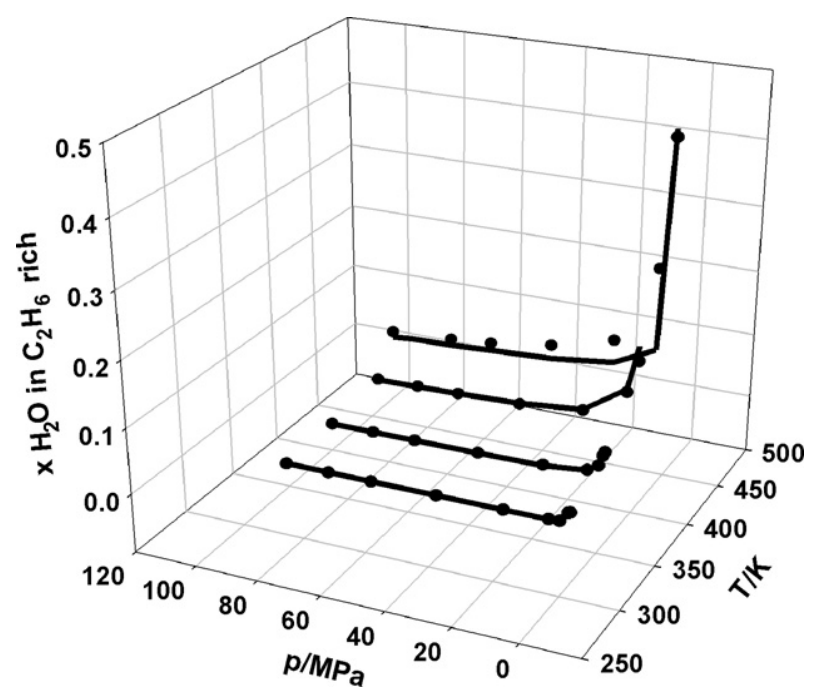

Fig. 2. Water solubility in the ethane-rich phase (experimental ( ) and CPA results using $\left.k_{i j}=0.141(-)\right)$.

Although the solubility of water in hydrocarbons is well described in the entire pressure and temperature range and so is the solubility of hydrocarbons in water above room temperature, the CPA EoS is not able to describe the well known minimum on the aqueous solubility of hydrocarbons at low temperatures. Usually, it is established that the enthalpy of solution includes two effects: a positive enthalpy of cavitation and a negative enthalpy of hydrophobic interaction between the hydrocarbon and water. These two effects cancel each other at the temperature at which the alkane solubility goes through a minimum with the enthalpy of cavitation becoming the dominant effect at higher temperatures than the minimum [55]. The inability of this and other equations of state to describe the data on this region is not a fitting problem but a limitation at a fundamental level of the equation of state (description of interactions in the system, like the hydrophobic effect). Results for two of these compounds are presented in Fig. 3.

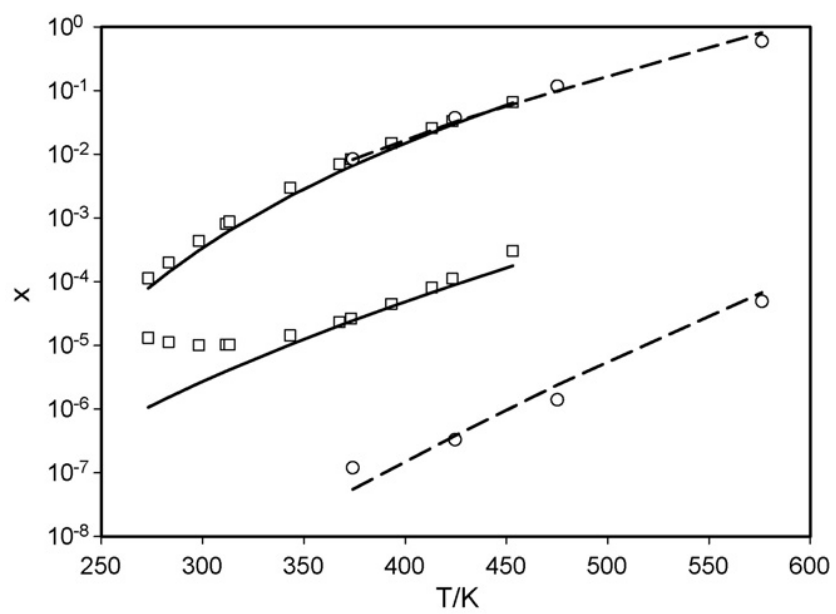

Fig. 3. Mutual solubilities for pentane + water (experimental ( $\square$ ) and CPA results using $k_{i j}=0.068(-)$ ) and for decane + water (experimental $(\bigcirc)$ ) and CPA results using $\left.k_{i j}=-0.054(--)\right)$. 
Table 3

Deviations in the water + aromatic mutual solubilities expressed in mol fractions obtained from CPA and respective cross-association volume and binary interaction parameter values

\begin{tabular}{|c|c|c|c|c|}
\hline \multirow[t]{2}{*}{ Compound } & \multirow[t]{2}{*}{$k_{i j}$} & \multirow[t]{2}{*}{$\beta_{\mathrm{ij}}$} & \multicolumn{2}{|l|}{ AAD $\%$} \\
\hline & & & $\begin{array}{l}x \text { hydrocarbon in } \\
\text { water-rich phase }\end{array}$ & $\begin{array}{l}x \text { water in hydrocarbon-rich } \\
\text { phase }\end{array}$ \\
\hline Benzene & 0.047 & 0.089 & 8.1 & 6.1 \\
\hline Toluene & 0.008 & 0.068 & 26.9 & 34.2 \\
\hline$o$-Xylene & -0.022 & 0.051 & 18.4 & 13.3 \\
\hline$m$-Xylene & 0.001 & 0.074 & 33.6 & 18.1 \\
\hline$p$-Xylene & -0.054 & 0.063 & 23.9 & 36.8 \\
\hline 1,3,5-Trimethylbenzene & -0.011 & 0.063 & 21.9 & 21.6 \\
\hline Ethylbenzene & -0.016 & 0.051 & 22.3 & 13.5 \\
\hline Propylbenzene & 0.012 & 0.059 & 17.8 & 15.9 \\
\hline Butylbenzene & -0.048 & 0.020 & 15.2 & 16.2 \\
\hline Pentylbenzene & -0.050 & 0.039 & 20.4 & 21.9 \\
\hline Isopropilbenzene & -0.057 & 0.046 & 20.7 & 5.1 \\
\hline Styrene & 0.033 & 0.079 & 16.7 & 17.1 \\
\hline Average deviation & & & 20.5 & 18.3 \\
\hline
\end{tabular}

Using data from methane to decane it was possible to establish a generalized correlation for the binary interaction parameter with the carbon number described by Eq. (11):

$k_{i j}=-0.0243 C_{n}+0.1894$

Using this correlation the phase equilibria of water $+n$ alkanes systems can be accurately predicted with the CPA EoS. Some numerical comparisons can be made with the results provided by the Elliot-Suresh-Donohue EoS, a method used to model the phase equilibria of hydrocarbon/water systems (from pentane to decane) in the work of Grenner et al. [24]. The superior CPA's capability to describe the aqueous phase is demonstrated by its global average deviation of only $32 \%$ for the hydrocarbon solubility in the water rich phase against the $84 \%$ provided by the Elliot-Suresh-Donohue EoS for the same solubility [24]. The binary interaction parameters used in the ESD EoS are also higher compared to the ones used in this work (up to 0.24 in ESD EoS and up to 0.068 in CPA EoS).

The experimental data for mutual solubilities of aromatics and water was available in a broad range of temperatures but only for low and medium pressures, as expected for liquid compounds at atmospheric pressure [59-62]. Although the aromatic hydrocarbons are themselves non-self-associating, it is well known that aromatic compounds are able to cross associate (solvate) with water $[37,38,63]$. A solvation scheme involving combining rules for the cross-associating energy and volume parameters [30] was here employed. Using this approach both the binary interaction parameter $k_{i j}$ and the cross-association volume $\beta^{\mathrm{A}_{i} \mathrm{~B}_{j}}$ are fitted to experimental equilibrium data. During the modeling it was observed that the inclusion of a binary interaction parameter $k_{i j}$ improves the representation of the hydrocarbon solubility in the water rich phase with no significant impact on the water solubility in the hydrocarbon phase. The solubility on the hydrocarbon phase is controlled by the cross-association volume $\beta^{\mathrm{A}_{i} \mathrm{~B}_{j}}$. Results for the phase equilibria were obtained with global average deviations of $21 \%$ for the aqueous phase and of $18 \%$ for the hydrocarbon rich phase. Deviations for each system studied as well as the values for the binary interaction parameter and cross-association volume are reported in Table 3. Results for selected systems are presented in Figs. 4-7.

The $\pi$ orbital associated to a double bound between two carbon atoms also turns these compounds into electron donors in a process similar to that observed for aromatic hydrocarbons. So styrene can cross associate with water either through the double bound or through the aromatic ring, being thus necessary to take into account this cross association. In fact, a improved representation of the LLE curve was possible if the solvation phenomena with water is taken into account instead of considering only water to be self-associating [20], being both solubilities described with average errors inferior to $18 \%$.

For most of the aromatic hydrocarbons, if the critical properties were used instead of the fitted pure compound parameters, the mutual solubilities could also be well described. The only difference would be that the values of the required binary interaction parameters would be higher than those obtained using

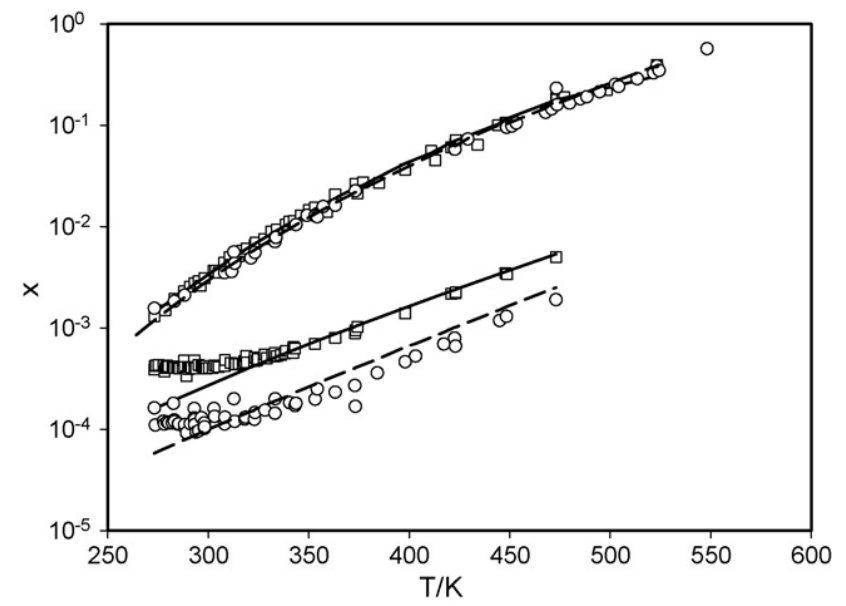

Fig. 4. Mutual solubilities for benzene + water (experimental ( $\square$ ) and CPA results using $k_{i j}=0.047, \beta_{i j}=0.089(-)$ ) and for toluene + water (experimental (O) and CPA results using $\left.k_{i j}=0.008, \beta_{i j}=0.068(--)\right)$. 


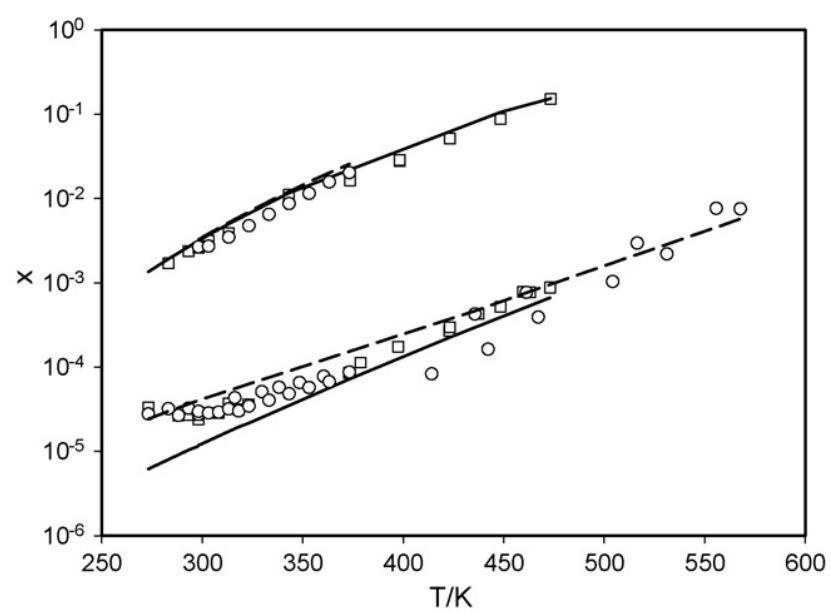

Fig. 5. Mutual solubilities for m-xylene + water (experimental ( $\square$ ) and CPA results using $\left.k_{i j}=0.001, \beta_{i j}=0.074(-)\right)$ and for p-xylene + water (experimental $(\bigcirc)$ and CPA results using $k_{i j}=-0.054, \beta_{i j}=0.063(---)$ ).

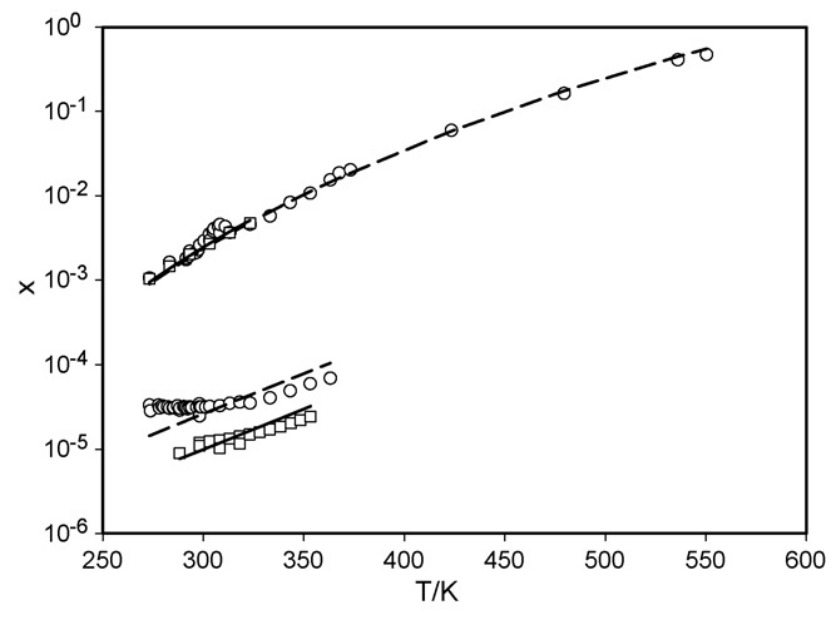

Fig. 6. Mutual solubilities for isopropilbenzene + water (experimental ( $\square$ ) and CPA results using $\left.k_{i j}=-0.057, \beta_{i j}=0.046(-)\right)$ and for ethylbenzene + water (experimental $(\bigcirc)$ and CPA results using $k_{i j}=-0.016, \beta_{i j}=0.051(---)$ ).

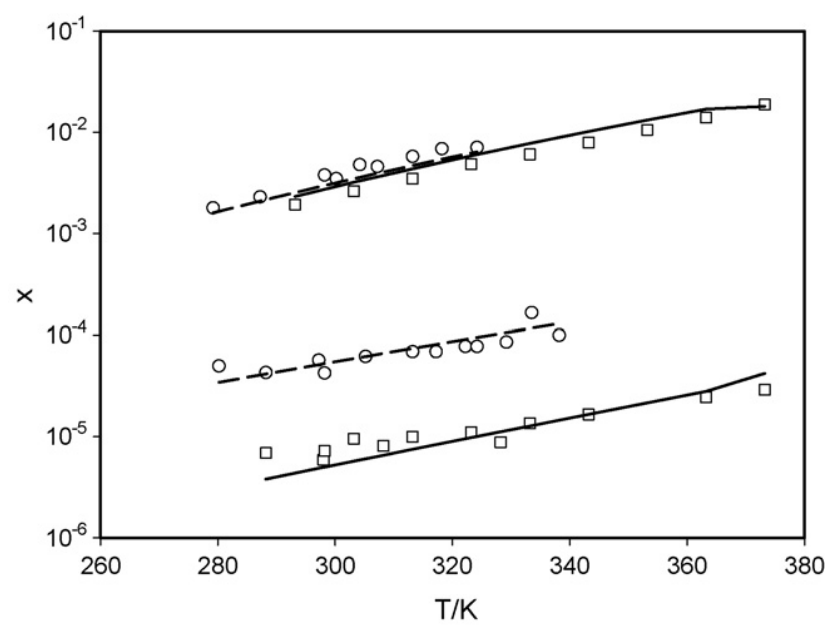

Fig. 7. Mutual solubilities for 1,3,5-trimethylbenzene + water (experimental ( $\square$ ) and CPA results using $\left.k_{i j}=-0.011, \beta_{i j}=0.063(-)\right)$ and for styrene + water (experimental $(\bigcirc)$ and CPA results using $k_{i j}=0.033, \beta_{i j}=0.079(---)$ ). the optimized pure components parameters. The model thus seems to account for the solvation phenomena existent in these systems more satisfactorily when the estimated parameters are used. Although the capability of using critical properties is an advantage for simple compounds for which these properties are available, for more complex hydrocarbon molecules for which nor experimental critical properties neither adequate estimation methods are available the possibility of fitting the pure compound parameters to actual experimental and easily accessible data such as vapor pressures and densities seems to be an advantage of the CPA approach over the conventional cubic equation of state approach.

The excellent results obtained in this work for hydrocarbons + water systems encourage the extension of this work towards more complex molecules and the modeling of the solubility of polyaromatic hydrocarbons (PAHs) and other more complex organic pollutants is currently under study. The PAHs compounds are generated during partial combustion of organic compounds and originated from motor vehicle exhausts, industrial combustion and domestic heating or released during oil spills. These xenobiotics must be monitored due to their impact on public health and the environment, because of their carcinogenic properties and their ubiquity in the environment [64].

\section{Conclusions}

In this work the cubic plus association (CPA) equation of state was applied to describe the mutual solubilities of several aliphatic and aromatic hydrocarbons and water.

In the case of the aliphatic hydrocarbons it was possible to satisfactorily describe the mutual solubilities through the ranges of temperature and pressure selected in this work with low average deviations. A single temperature independent binary interaction parameter (in the physical term) fitted to the experimental data is enough and is shown that it correlates well linearly with the carbon number of the $n$-alkane. This demonstrates how the CPA EoS can be used as a predictive tool for the $n$-alkane + water systems.

It was shown that the solvation phenomena between a selfassociating molecule and a non-self-associating molecule, that takes place in the aromatics + water systems, can be successfully modeled with a cross-association approach.

The ability of the CPA EoS for describing the phase equilibria of hydrocarbons + water systems was successfully demonstrated for a large number of compounds in a broad range of pressures and temperatures.

$\begin{array}{ll}\begin{array}{l}\text { List of symbols } \\ a\end{array} & \text { energy parameter in the physical term } \\ a_{0}, c_{1} & \text { parameters for calculating } a \\ \mathrm{~A}_{i} & \text { site A in molecule } i \\ b & \text { co-volume } \\ g & \text { radial distribution function } \\ G & \text { Gibbs energy } \\ k_{i j} & \text { binary interaction parameters } \\ P & \text { vapor pressure } \\ R & \text { gas constant }\end{array}$


$T$

temperature

$x \quad$ mole fraction

$X_{\mathrm{A}} \quad$ fraction of molecule not bonded at site A

Z compressibility factor

\section{Greek letters}

$\beta \quad$ association volume

$\Delta \quad$ association strength

$\varepsilon \quad$ association energy

$\eta \quad$ reduced fluid density

$\rho \quad$ mole density

\section{Subscripts}

$i, j \quad$ pure component indexes

liq. liquid

r reduced

\section{Superscripts}

assoc. association

calc. calculated

exp. experimental

E excess

phys. physical

\section{Acknowledgements}

This work was supported by Fundação para a Ciência e a Tecnologia through project POCI/EQU/58239/2004: "Equilibrium and Interfacial Properties of Water + Oil Systems".

Mariana B. Oliveira acknowledges the financial support from Fundação para a Ciência e a Tecnologia through her $\mathrm{PhD}$ (SFRH/BD/29062/2006) scholarship.

\section{References}

[1] C. Tsonopoulos, G.M. Wilson, AlChE J. 29 (1983) 990-999.

[2] W. Zhang, J.W. Wilder, D.H. Smith, AlChE J. 48 (2002) 2324-2331.

[3] D. Avlonitis, AlChE J. 51 (2005) 1258-1273.

[4] T. Uchida, M. Moriwaki, S. Takeya, I.Y. Ikeda, R. Ohmura, J. Nagao, H. Minagawa, T. Ebinuma, H. Narita, K. Gohara, S. Mae, AlChE J. 50 (2004) 518-523.

[5] I.G. Economou, C. Tsonopoulos, Chem. Eng. Sci. 52 (1997) 511-525.

[6] S.H. Yalkowsky, S.C. Valvani, J. Chem. Eng. Data 24 (1979) 127-129.

[7] D.L. Peterson, S.H. Yalkowsky, J. Chem. Inf. Comput. Sci. 41 (2001) 1531-1534.

[8] F. Giralt, G. Espinosa, A. Arenas, J. Ferre-Gine, L. Amat, X. Girones, R. Carbo-Dorca, Y. Cohen, AlChE J. 50 (2004) 1315-1343.

[9] J. Sedlbauer, G. Bergin, V. Majer, AlChE J. 48 (2002) 2936-2959.

[10] E.C. Voutsas, D.P. Tassios, Ind. Eng. Chem. Res. 36 (1997) 4965-4972.

[11] H.H. Hooper, S. Michel, J.M. Prausnitz, Ind. Eng. Chem. Res. 27 (1988) 2182-2187.

[12] E.C. Voutsas, D.P. Tassios, Ind. Eng. Chem. Res. 36 (1997) 4973-4976.

[13] S.R. Sherman, D.B. Trampe, D.M. Bush, M. Schiller, C.A. Eckert, A.J. Dallas, J.J. Li, P.W. Carr, Ind. Eng. Chem. Res. 35 (1996) 1044-1058.

[14] M. Akia, F. Feyzi, AlChE J. 52 (2005) 333-341.

[15] M.C. Wang, D.S.H. Wong, Fluid Phase Equilib. 227 (2005) 183-196.

[16] A. Klamt, Fluid Phase Equilib. 206 (2003) 223-235.

[17] C. Bidart, H. Segura, J. Wisniak, Ind. Eng. Chem. Res. 46 (2007) 947-954.

[18] J.C. de Hemptinne, P. Mougin, A. Barreau, L. Ruffine, S. Tamouza, R. Inchekel, Oil \& Gas Science and Technology-Revue De L Institut Francais Du Petrole 61 (2006) 363-386.
[19] G.M. Kontogeorgis, M.L. Michelsen, G.K. Folas, S. Derawi, N. von Solms, E.H. Stenby, Ind. Eng. Chem. Res. 45 (2006) 4855-4868.

[20] G.M. Kontogeorgis, M.L. Michelsen, G.K. Folas, S. Derawi, N. von Solms, E.H. Stenby, Ind. Eng. Chem. Res. 45 (2006) 4869-4878.

[21] X.S. Li, H.J. Wu, P. Englezos, Ind. Eng. Chem. Res. 45 (2006) 2131-2137.

[22] E.C. Voutsas, G.C. Boulougouris, I.G. Economou, D.P. Tassios, Ind. Eng. Chem. Res. 39 (2000) 797-804.

[23] T. Kraska, K.E. Gubbins, Ind. Eng. Chem. Res. 35 (1996) 4738-4746.

[24] A. Grenner, J. Schmelzer, N. von Solms, G.M. Kontogeorgis, Ind. Eng. Chem. Res. 45 (2006) 8170-8179.

[25] E.K. Karakatsani, G.M. Kontogeorgis, I.G. Economou, Ind. Eng. Chem. Res. 45 (2006) 6063-6074.

[26] F. Blas, PhD Thesis Universitat Rovira et Virgili, Tarragona, Spain (2000).

[27] S.J. Suresh, J.R. Elliott, Ind. Eng. Chem. Res. 31 (1992) 2783-2794.

[28] J.Z. Wu, J.M. Prausnitz, Ind. Eng. Chem. Res. 37 (1998) 1634-1643.

[29] I.V. Yakoumis, G.M. Kontogeorgis, E.C. Voutsas, E.M. Hendriks, D.P. Tassios, Ind. Eng. Chem. Res. 37 (1998) 4175-4182.

[30] G.K. Folas, G.M. Kontogeorgis, M.L. Michelsen, E.H. Stenby, Ind. Eng. Chem. Res. 45 (2006) 1527-1538.

[31] G.K. Folas, J. Gabrielsen, M.L. Michelsen, E.H. Stenby, G.M. Kontogeorgis, Ind. Eng. Chem. Res. 44 (2005) 3823-3833.

[32] S.O. Derawi, G.M. Kontogeorgis, M.L. Michelsen, E.H. Stenby, Ind. Eng. Chem. Res. 42 (2003) 1470-1477.

[33] M.B. Oliveira, M.G. Freire, I.M. Marrucho, G.M. Kontogeorgis, A.J. Queimada, J.A.P. Coutinho, Ind. Eng. Chem. Res. 46 (2007) 1415-1420.

[34] M.L. Michelsen, E.M. Hendriks, Fluid Phase Equilib. 180 (2001) 165-174.

[35] G.M. Kontogeorgis, I.V. Yakoumis, H. Meijer, E. Hendriks, T. Moorwood, Fluid Phase Equilib. 160 (1999) 201-209.

[36] E.C. Voutsas, I.V. Yakoumis, D.P. Tassios, Fluid Phase Equilib. 160 (1999) 151-163.

[37] R.L. Brinkley, R.B. Gupta, AlChE J. 47 (2001) 948-953.

[38] P. Tarakeshwar, H.S. Choi, S.J. Lee, J.Y. Lee, K.S. Kim, T.K. Ha, J.H. Jang, J.G. Lee, H. Lee, J. Chem. Phys. 111 (1999) 5838-5850.

[39] Design Institute for Physical Property Data, DIPPR Database, AIChE, New York (1998).

[40] M.B. Oliveira, I.M. Marrucho, J.A.P. Coutinho, A.J. Queimada, J. Colloid Interf. Sci., in press.

[41] A. Dhima, J.C. de Hemptinne, G. Moracchini, Fluid Phase Equilib. 145 (1998) 129-150.

[42] T.D. Osulliva, N.O. Smith, J. Phys. Chem. 74 (1970) 1460.

[43] K. Lekvam, P.R. Bishnoi, Fluid Phase Equilib. 131 (1997) 297-309.

[44] R. Kobayashi, D.L. Katz, Ind. Eng. Chem. 45 (1953) 446-451.

[45] A.H. Wehe, J.J. Mcketta, Anal. Chem. 33 (1961) 291.

[46] J.J. Carroll, F.Y. Jou, A.E. Mather, Fluid Phase Equilib. 140 (1997) $157-169$.

[47] A.H. Mohammadi, A. Chapoy, D. Richon, B. Tohidi, Ind. Eng. Chem. Res. 43 (2004) 7148-7162.

[48] A.H. Mohammadi, A. Chapoy, B. Tohidi, D. Richon, Ind. Eng. Chem. Res. 45 (2006) 4825-4829.

[49] A. Chapoy, C. Coquelet, D. Richon, Fluid Phase Equilib. 214 (2003) 101-117.

[50] A.H. Mohammadi, A. Chapoy, B. Tohidi, D. Richon, Ind. Eng. Chem. Res. 43 (2004) 5418-5424.

[51] M. Yarrison, K.R. Cox, W.G. Chapman, Ind. Eng. Chem. Res. 45 (2006) 6770-6777.

[52] A. Chapoy, S. Mokraoui, A. Valtz, D. Richon, A.H. Mohammadi, B. Tohidi, Fluid Phase Equilib. 226 (2004) 213-220.

[53] T.L. Tian, X.F. Zhao, L. Chen, H.G. Zhu, H.F. Fu, J. Supercrit. Fluids 30 (2004) 145-153.

[54] H.H. Reamer, B.H. Sage, W.N. Lacey, Ind. Eng. Chem. 44 (1952) 609-615.

[55] J.L. Heidman, C. Tsonopoulos, C.J. Brady, G.M. Wilson, AlChE J. 31 (1985) 376-384.

[56] I.G. Economou, J.L. Heidman, C. Tsonopoulos, G.M. Wilson, AlChE J. 43 (1997) 535-546.

[57] C. Tsonopoulos, Fluid Phase Equilib. 186 (2001) 185-206.

[58] C. Tsonopoulos, Fluid Phase Equilib. 156 (1999) 21-33.

[59] M. Goral, B. Wisniewska-Goclowska, A. Maczynski, J. Phys. Chem. Ref. Data 33 (2004) 1159-1188. 
[60] A. Maczynski, D.G. Shaw, M. Goral, B. Wisniewska-Goclowska, A. Skrzecz, I. Owczarek, K. Blazej, M.C. Haulait-Pirson, G.T. Hefter, F. Kapuku, Z. Maczynska, A. Szafranski, C.L. Young, J. Phys. Chem. Ref. Data 34 (2005) 1399-1487.

[61] D.G. Shaw, A. Maczynski, M. Goral, B. Wisniewska-Goclowska, A Skrzecz, I. Owczarek, K. Blazej, M.C. Haulait-Pirson, G.T. Hefter, Z. Maczynska, A. Szafranski, J. Phys. Chem. Ref. Data 34 (2005) 14891553.
[62] D.G. Shaw, A. Maczynski, M. Goral, B. Wisniewska-Goclowska, A Skrzecz, I. Owczarek, K. Blazej, M.C. Haulait-Pirson, G.T. Hefter, F. Kapuku, Z. Maczynska, A. Szafranski, J. Phys. Chem. Ref. Data 34 (2005) 2299-2345.

[63] B.M. Hasch, E.J. Maurer, L.F. Ansanelli, M.A. Mchugh, J. Chem. Thermodyn. 26 (1994) 625-640.

[64] H. Carrere, A. Bernal-Martinez, D. Patureau, J.P. Delgenes, AlChE J. 52 (2006) 3612-3620. 